\title{
A 30-year multi-proxy reconstruction of PAGES' history
}

Thorsten Kiefer ${ }^{1}$ and Marie-France Loutre ${ }^{2}$

\begin{abstract}
At its core, the mission of the Past Global Changes project has remained remarkably consistent over 30 years, fostering interdisciplinarity and international collaboration to better understand and predict environmental change. The hows and whos, however, have evolved dynamically as challenges and opportunities changed over time.
\end{abstract}

Thirty years of history is a good reason for PAGES to celebrate but also to reflect on the timeliness of the endeavor. On the 20th anniversary of PAGES, one devil's advocate asked whether it wasn't time to wrap up and make room for something new. At the time, we considered the idea (only very briefly). Today, although 10 years older, PAGES is still as youthful and dynamic as ever, though in different ways. From paleoecology we know that for long-term survival and success of a species, a society or an ecosystem is required to evolve with the changing ambient conditions. The same appears to apply to international organizations in the dynamic landscape of research and innovation.

In this article, we reconstruct key indicators of the history of PAGES. As the current and previous director of PAGES, we have access to accumulated direct observations from over 15 years. Unfortunately, this reaches only halfway back to the inception of PAGES in the year $1991 \mathrm{CE}$. The history beyond direct observations therefore relies on reconstructions based on proxy data from historical documents and anecdotal evidence. As with any good paleoscientific work, we base our interpretations on occasionally patchy, potentially biased, and uncertain evidence to generate a coherent conclusion.

\section{Science}

The PAGES newsletters of the early 90 s reveal that the initial focus was on pushing paleoscience research internationally, with members of the Scientific Steering Committee (SSC) advocating the paleoscience areas for which they were globally recognized pioneers. This led seamlessly into sharing the results and the excitement of existing paleoscientific projects and programs with the global PAGES community by endorsing major ongoing paleoscience

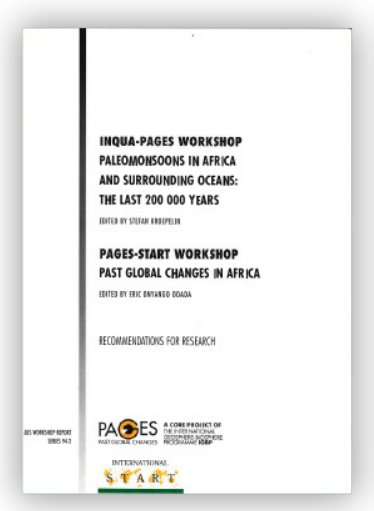

Report (1994)

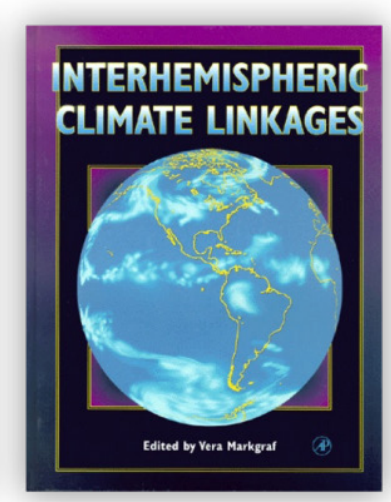

Book (2001)

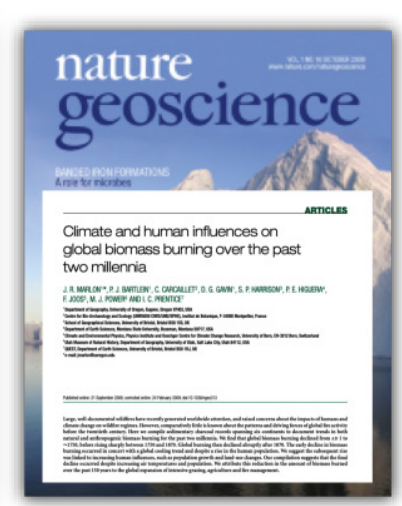

Paper (2008)

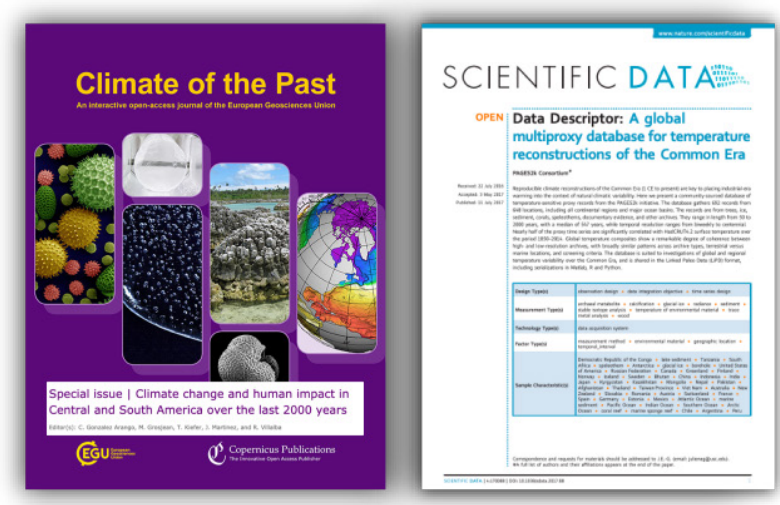

Special issue (2015) Database (2017)

Figure 1: Examples of popular publication formats through time (Kroepelin and Odada 1994; Markgraf 2001; Marlon et al. 2008; Gonzalez Arango et al. 2015; PAGES2k Consortium 2017).

initiatives, such as ice-core work in Greenland (GRIP, GISP2) and continental deep drilling (ICDP).

The first Science Plan, published in 1994 formally cast this emerging structure into an array of focus areas that has largely continued to mark the scope of PAGES to today. The focus areas became home to emblematic, big programs that attracted attention, presumably also funding for individual projects, and certainly engagement of researchers across areas of the globe that had so far collaborated only sporadically. The Science Plan was designed to foster this with global programs, such as Paleoclimate and Environments of the Northern and Southern Hemispheres (PANASH), with its three meridional Pole-Equator-Pole (PEP) transects, or the International Marine Past Global Change Study (IMAGES), with its game-changing paleoceanographic sediment-coring campaigns.

In the late 2000s it became apparent that the formerly dynamic PAGES programs might become stale after many years of existence and occupy resources that could otherwise be used for new developments. This led to the establishment of a rolling system of working groups with a limited lifetime, initiated by the community, and quality-checked by the SSC. Each group proposes final goals and outcomes in its initial proposal, thus allowing PAGES to evaluate its progress over the course of three to six years, then declare victory, sunset the working group and head for new shores. The move towards a fasterspinning machine, fueled by the innovative ideas coming from the community, resulted in the creation of more than 40 working groups since 2006 and accelerated the continuous innovation cycle that may well contribute to PAGES' youthful appearance to this day.

Another striking evolution of PAGES relates to the kind of primary scientific publications resulting from PAGES' activities (Fig. 1). The pioneers of PAGES loved to produce pretty reports that were quick to flick through, appealing to look at, and a pleasure to read. The next generation produced hard-cover books that summarized copious amounts of information, suitable also to take pride of place on every paleoscientist's bookshelf. With the dawn of the new millennium, however, reports and books were abandoned, as peer-reviewed scientific papers rose in popularity: succinct, quality-validated, citable, downloadable, and increasingly 
career-relevant for the authors. Several community papers in high-profile journals have contributed to raising the profile of PAGES' approach to generate excellence through global collaboration.

While the regard for academic papers remains high to this day, a competitor (or complement) recently entered the stage in the form of databases and data products, such as those on the climate of the past 2000 years, paleofire, and speleothems. This nicely converges back to a vision of PAGES' pioneers for global data sharing through comprehensive paleoscience data centers. It will be interesting to see what product formats will characterize PAGES' next decade.

\section{Community}

The centerpiece of PAGES today is uncontestably its global community of active researchers and other experts. They believe in the power of collaboration to drive forward their field of science with passion, recognizing that the energy and creativity of the community accelerates their individual research objectives.

In its inaugural days, PAGES was driven by world leaders in the still-young disciplines of paleoclimatic and paleoenvironmental science. They had the scientific standing and the exciting research projects at their fingertips to raise a strong profile for the newly founded PAGES project. In the late 90 s and early 2000s, PAGES created entry points for participation by paleoscientists from different disciplines worldwide. Since the late 2000s, all members and followers of the paleoscience community can propose and, if successful, run a working group to contribute to the advancement of paleoscientific understanding and capacity.

Finally, over the last decade, the PAGES community witnessed a spectacular diversification, not only scientifically and geographically, but also by achieving healthy balances

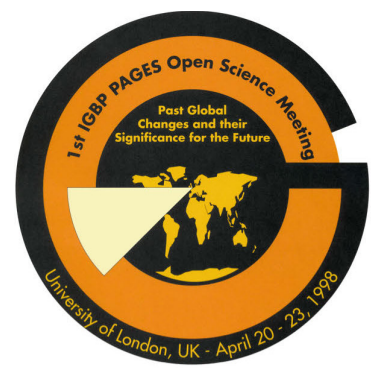

London (1998)

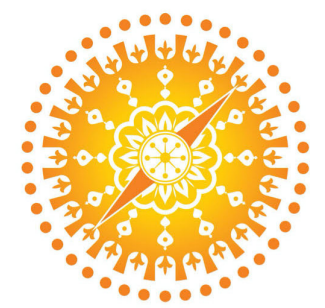

pages goa 2013

4TH OPEN SCIENCE MEETING THE PAST: A COMPASS FOR FUTURE EARTH 16 FEBRUARY

Goa (2013)

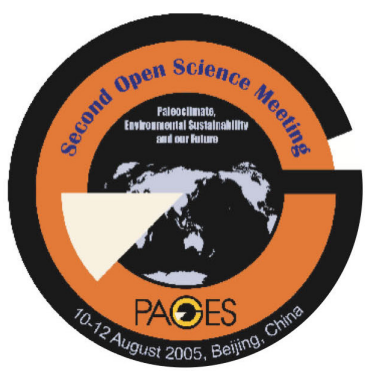

Beijing (2005)

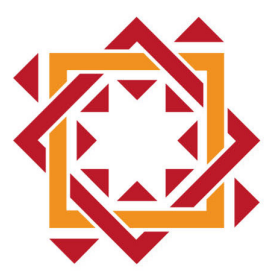

PAGES Zaragoza 2017

5th Open Science Meeting

Global Challenges for our Common Future: a paleoscience perspective

Zaragoza (2017)

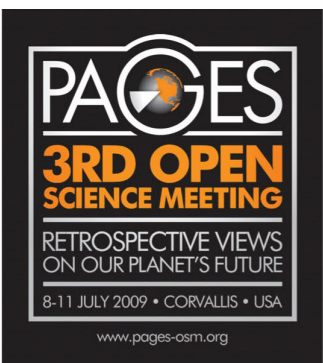

Corvallis (2009)

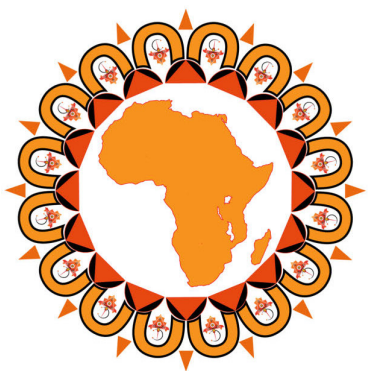

PAGES AGADIR 2022

6th Open Science Meeting

Learning from the past for a sustainable future

Agadir (2022)

Figure 2: Logos of all five PAGES Open Science Meetings that have taken place so far and of the one to look forward to in 2022

of gender and across the career spectrum. The early-career researchers, specifically targeted with a first Young Scientists Meeting (YSM) in 2009, are today a driving force in PAGES through regular YSMs, our own EarlyCareer Network, and a seat on the SSC.

Once every few years the PAGES community gathers at the Open Science Meeting (OSM). Meetings during the years 1998, 2005,

2009, 2013, and 2017 were held in London, Beijing, Corvallis, Goa, and Zaragoza (Fig. 2). Writing this article during the pandemic years 2020/21, it is not without melancholy that we recall many in-person paleoscientific exchanges with international colleagues at those locations. If you need something to look forward to, mark your calendar with the upcoming OSM in Agadir, Morocco, from 15-21 May 2022!

\section{Communication}

Probably the most visible and continuous expressions of how PAGES, and indeed the world, has evolved over the last three decades are our means of communication. To get a sense of how long PAGES has been around, consider that it existed for several years without a web presence - unthinkable today, but the norm back in the early $90 \mathrm{~s}$. It

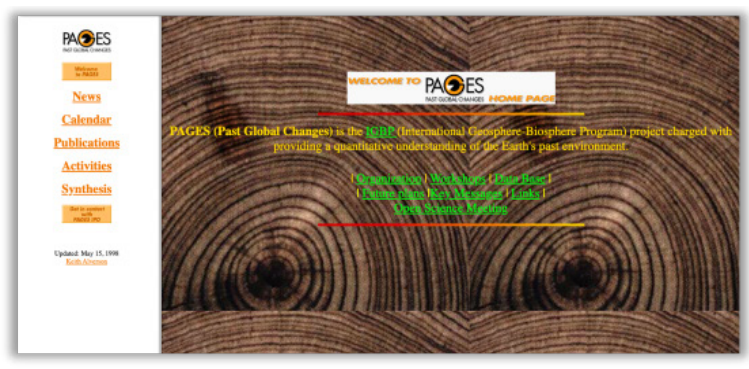

1998

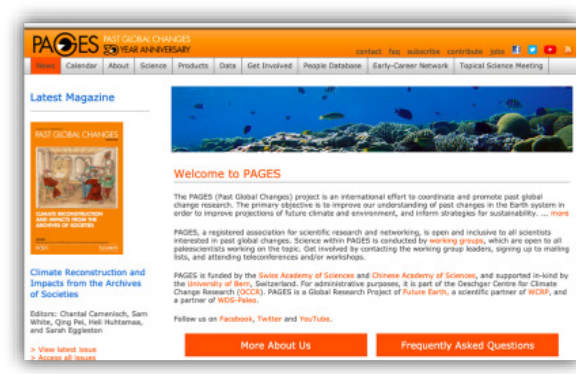

2014

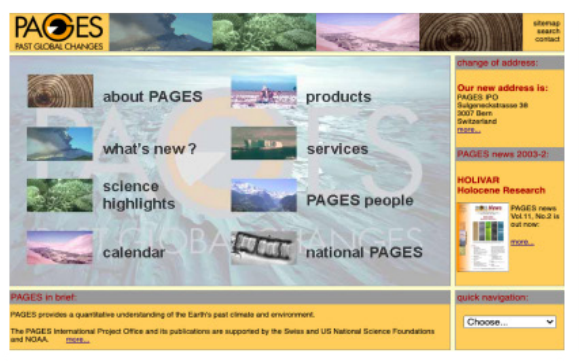

2003

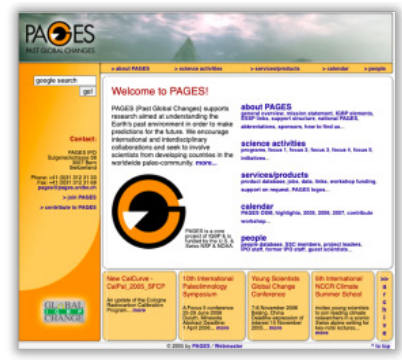

2005

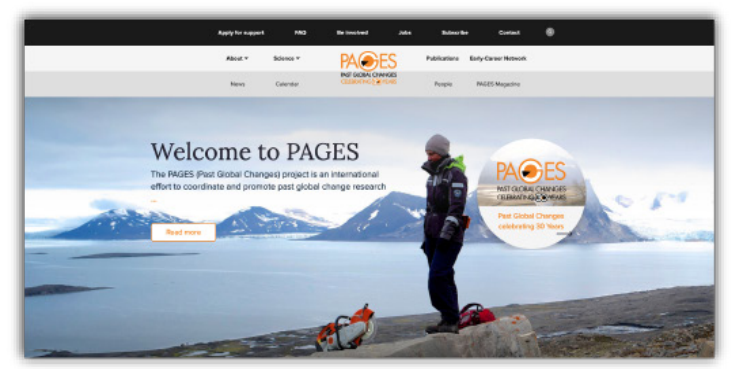

2021

Figure 3: Different designs of the PAGES website since its establishment in 1997. 
was not until 1997 that PAGES' first website went live, initially hosted by NOAA, then soon afterward by the University of Bern. Since then, the website has been the main point of reference for information and a resource for PAGES products. Figure 3 invites you to travel through different times of web design and to enjoy the brand-new website that was launched to celebrate PAGES' 30th anniversary.

Another extremely important PAGES outlet is its magazine. PAGES news was launched in 1993 as a compact four-page leaflet, printed and mailed to subscribers (Fig. 4). Since then, it has grown considerably in size and scope, including more and more information about PAGES' scientific activities and findings. In April 1997, for the first time, a thematic focus was published in PAGES news, emphasizing the activities going on within two of the three PEP Transects and soliciting article contributions from experts within the PAGES community. The concept of an appealing in-house publication with a core of scientific articles that are sometimes even cited in peer-reviewed papers has persisted ever since. In 2014, PAGES took the obvious step to rename its publication into what it had actually become, a magazinestyle publication with relevance not only for the PAGES project but with recognition in the field of paleoscience and beyond: Past Global Changes Magazine, impossible to miss in its bright orange design, was born.

With the rise of electronic mail, PAGES moved the spread of network information such as upcoming events, deadlines, and activities from the printed PAGES news to the much faster medium of email. In 2001, the first PAGES e-news was sent out, making sure that subscribers received information about opportunities well before the deadlines. What seemed fast at the time is slow today. Since PAGES entered the social media world in 2010, information is shared also as decentralized, real-time updates and interactive exchanges via Twitter and Facebook - but fear not, recent polls have revealed that a critical mass of paleoscientists still appreciates their information spoon-fed in menu format and many even still appreciate reading the magazine on good old paper. Therefore, PAGES will continue with the e-news and magazine hardcopies into its fourth decade.

It is always the ultimate commendation when figures from the magazine are used in conference presentations and education. From 1994 to the early 2000s, PAGES offered its most iconic figures for copying or printing as overhead slides, and until 2016 all magazine figures were downloadable as PowerPoint files. While content-extraction software has now made separate provision of figures redundant, everyone should continue to feel welcome to use material from the PAGES website and Past Global Changes Magazine extensively for free (with an enthusiastic reference to PAGES, please ${ }^{1}$ ).

${ }^{1}$ To use material published by PAGES, please be sure to follow the CC-BY guidelines: creativecommons.org/licenses/by/4.0/

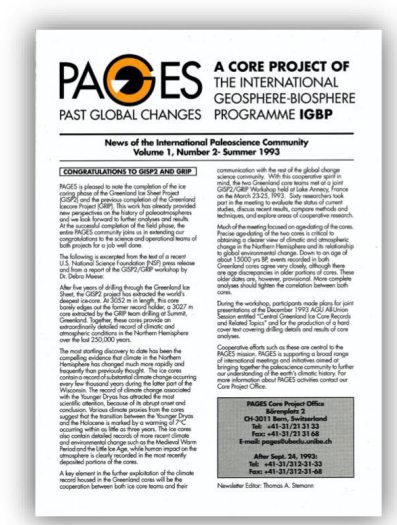

1993

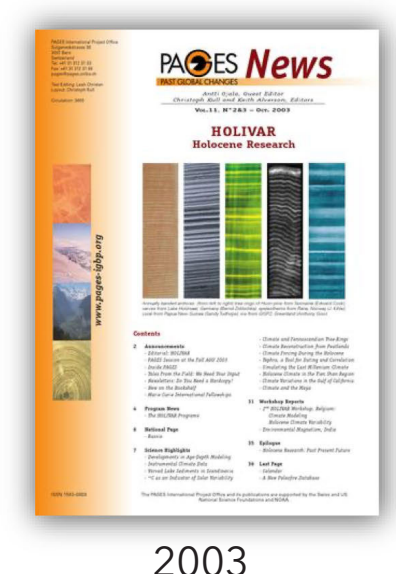

2003

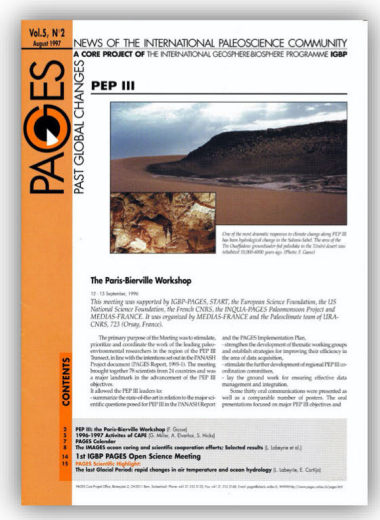

1997

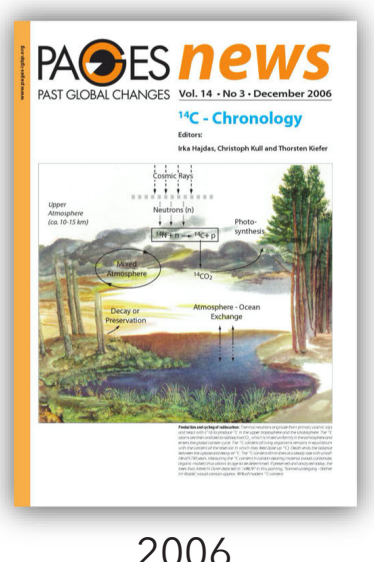

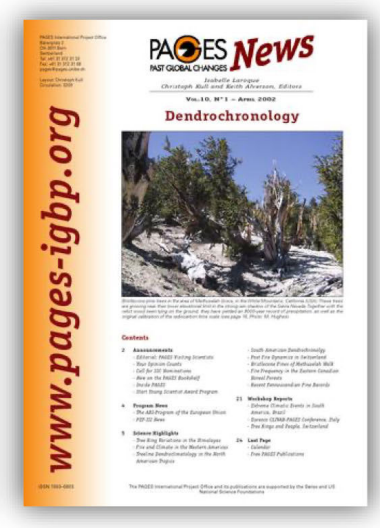

2002

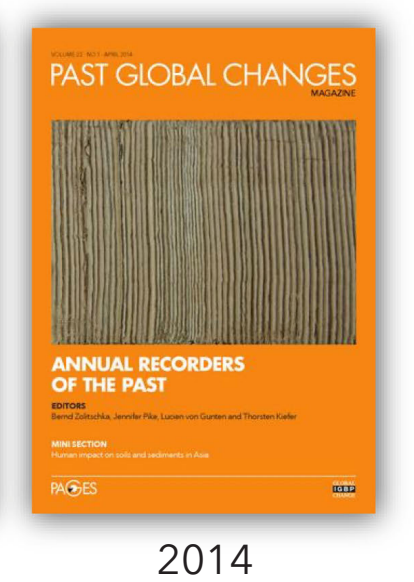

Figure 4: Stepwise evolution of the layout of Past Global Changes Magazine, formerly known as PAGES news.

\section{Behind the scenes}

Two more factors have been essential for the long life and success of PAGES. First, the generous long-term funding by the National Science Foundations of Switzerland and the US, substituted in 2019 by the Academies of Sciences of Switzerland and China, provided the necessary cash resources. With this foundation, PAGES was able to develop its science agenda and structure as described above to constantly improve the organization. (For more information on the history of funding and the players behind it see Fischer et al. this issue.)

Second, as the authors of this retrospective and as executive directors who cumulatively escorted PAGES through more than half of its lifetime, we pay tribute to the staff of the PAGES International Project Office. Under the guidance of five different executive directors, approximately 40 staff members have supported projects, liaised with the community, edited newsletters, created websites, updated content, administered finances, disseminated information, and contributed in many other ways to the establishment of PAGES as an efficient program with a dedicated mission and a friendly face.

To date, PAGES has almost 5500 subscribers: around 500 attend workshops each year, about 200 co-author articles in Past Global Changes Magazine each year, and almost 900 were at the last OSM in Zaragoza in 2017. With this crowd, the future of PAGES is bright! The 30 -year anniversary offers an opportune moment to look back with humble pride and look forward with vivid anticipation.

\section{AFFILIATIONS}

'Joint Programming Initiative Healthy and Productive

Seas and Oceans, Brussels, Belgium

2Past Global Changes International Project Office, Bern, Switzerland

CONTACT

Thorsten Kiefer: thorsten.kiefer@jpi-oceans.eu

\section{REFERENCES}

Gonzalez Arango C et al. (Eds) (2015) Climate change and human impact in Central and South America over the last 2000 years. Clim Past (special issue)

Kroepelin S, Odada EO (Eds) (1994) Paleomonsoons in Africa and surrounding oceans: The last 200,000 years/Past Global Changes in Africa. PAGES Workshop Report 94-2, 49 pp

Markgraf V (2001) Interhemispheric Climate Linkages. Academic Press, 454 pp

Marlon JR et al. (2008) Nat Geosci 1: 697-702

Hajdas I et al. (Eds) (2006) PAGES news 14, 32 pp

Larocque l et al. (Eds) (2002) PAGES news 10(1), 24 pp

Ojala A et al. (Eds) (2003) PAGES news 11(2-3), 36 pp

Oldfield F (Ed) (1997) PAGES news 5(2), 16 pp

PAGES2k Consortium (2017) Sci Data 4: 170088

Supplementary material

Stemann TA (Ed) (1993) PAGES news 1(2), 4 pp

Zolitschka B et al. (Eds) (2014) PAGES Mag 22(1), 56 pp 